\title{
ASTROPHYSICAL INTERESTING COMPOUND GRAINS PRODUCED BY A GAS EVAPORATION METHOD
}

\author{
C.KAITO and Y.SAITO \\ Department of Electronics and Information Science \\ Kyoto Institute of Technology \\ Matsugasaki Sakyo-ku Kyoto 606 Japan
}

\begin{abstract}
Production methods of $\mathrm{Fe}_{3} \mathrm{O}_{4}$ grain and $\mathrm{MgS}$ grain have been introduced. $\mathrm{Fe}_{3} \mathrm{O}_{4}$ grain was produced in an $\mathrm{Ar}$ gas pressure range of 25 to 100 Torr by evaporating $\mathrm{FeO}$ powder. The growth of $\mathrm{Fe}_{3} \mathrm{O}_{4}$ have been discussed as the result of oxidation of $\mathrm{Fe}$ grains. MgS grain produced by the reaction of $\mathrm{Mg}$ and $\mathrm{S}$ vapors grew in the coagulation of tiny cubic sulfide.
\end{abstract}

\section{INTRODUCTION}

The most advanced method for producing grains of metal or oxide is the so-called "gas evaporation method", in which a material is heated in inert gas atmosphere(Kimoto et al.(1963)). The heated vapor is subsequently cooled and condensed in the gas atmosphere, resulting in a smoke which looks like that of a candle. The direct evaporation of the oxide or sulfide in the gas was not always given the same components of the evaporant, i.e. decomposition took place (Kaito(1983)). We proposed various methods for producing compounds(Kaito (1981), Kaito et a1.(1989)), by using the convection $f$ low of inert gas. New attempts for production of $\mathrm{Fe}_{3} \mathrm{O}_{4}$ grain and the production of $\mathrm{MgS}$ grain are described in this paper.

\section{EXPERIMENTAL PROCEDURE}

The sample preparation chamber is a glass cylinder of $17 \mathrm{~cm}$ in inner diameter and $33 \mathrm{~cm}$ in height. A tantalum v-boat (length $50 \mathrm{~mm}$, width $2 \mathrm{~mm}$ and depth $1 \mathrm{~mm}$ ) charged with powder of $\mathrm{FeO}(99.9 \%)$ was p laced in the chamber. Ar gas at 10-100 Torr was introduced into the chamber and the boat heated up at about $1800^{\circ} \mathrm{C}$. Grains in the produced smoke were collected on thin carbon film supported by electron microscopic grids at various position in smoke and observed with a Hitachi H-800 electron microscope. The three-heater method which has been shown in a previous paper (Kaito et al (1990)) was applied for the production of MgS grains.

\section{7}

A.C. Levasseur-Regourd and H. Hasegawa (eds.), Origin and Evolution of Interplanetary Dust, 117-120.

C 1991 Kluwer Academic Publishers, Printed in Japan. 


\section{RESULTS AND DISCUSSION}

Typical smoke which formed by evaporating FeO in Ar gas at 100 Torr is shown in Fig.1(a). The evaporation source was almost perpendicular to the photographic plane. Figs. 1(b) and 1(c) show electron microscopic image and electron diffraction(ED) pattern from the grain collected in smoke shown in Fig.1(a). ED pattern shows the formation of magnetite. External shape of the we11-grown grains was cubic octahedron.

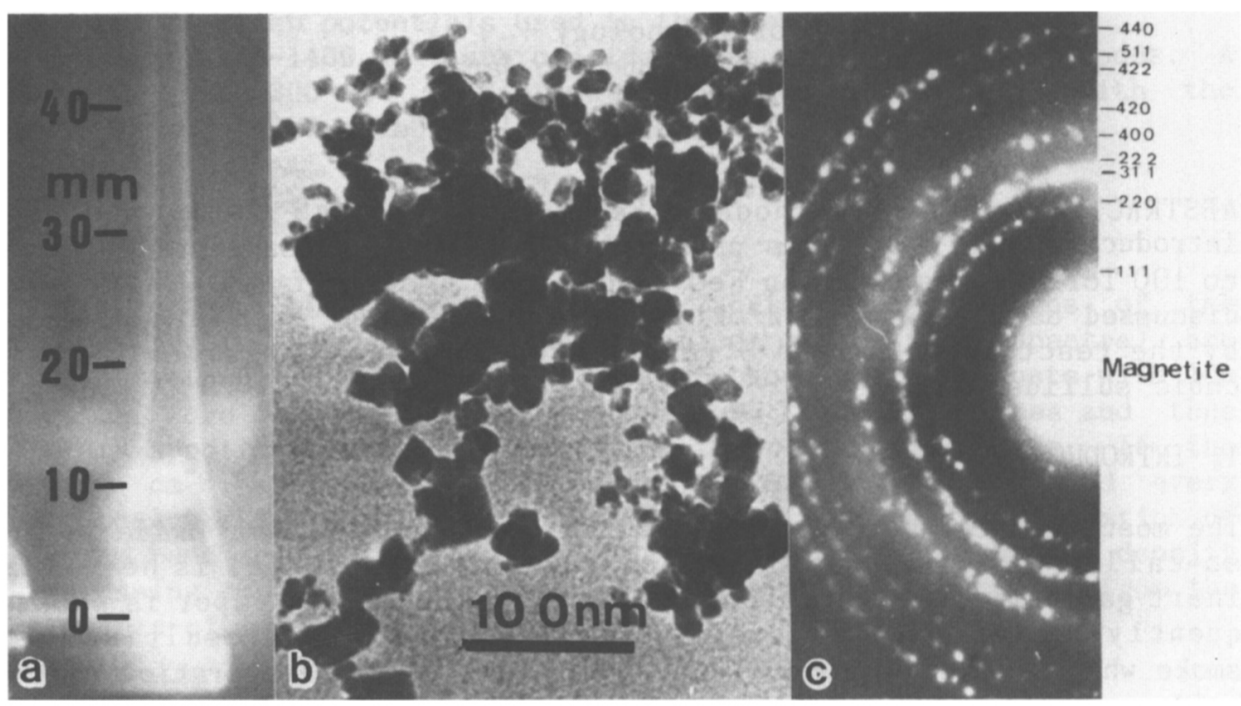

Fig.1. (a) Smoke of $\mathrm{Fe}_{3} \mathrm{O}_{4}$ grains formed by evaporating $\mathrm{FeO}$ powder in $\mathrm{Ar}$ gas at 100 Torr, (b) and (c) show electron microscopic image and electron diffraction pattern.

TABLE 1. Results of analyses of iron oxide grains

\begin{tabular}{lcccc}
\hline $\begin{array}{l}\text { Ar Gas Pressure (Torr) } \\
\text { Produced Grain }\end{array}$ & $\begin{array}{c}10 \\
\alpha-\mathrm{Fe}\end{array}$ & $\begin{array}{c}\alpha-\mathrm{Fe} \\
(\mathrm{FeO})\end{array}$ & $\begin{array}{c}17-20 \\
\mathrm{FeO}\end{array}$ & $\begin{array}{r}25-100 \\
\mathrm{Fe}_{3} \mathrm{O}_{4}\end{array}$ \\
\hline
\end{tabular}

() means the oxide produced on the surface of $\alpha-\mathrm{Fe}$

A summary of the produced grains due to gas pressure is shown in table 1 . The magnetite grains were predominantly produced above 25 Torr. At 10 Torr gas pressure, iron grains were produced. At 15 Torr gas pressure, $\mathrm{FeO}$ oxide (Wustite) was produced on the surface of iron. The grain of wustite predominantly appeared in gas pressures of 17-20 Torr. Produced grains were changed by the gas pressure of inert gas. 
These results show that the evaporated $\mathrm{FeO}$ powder was decomposed and oxidation took place in the atmosphere. The temperature of the grains became a few hundred degrees at a point about $10 \mathrm{~mm}$ above the evaporation source. The oxidation of iron grain took place near the heat source. Therefore the formation of various oxides by the gas pressure is due to variation of the oxygen gas density per unit volume in smoke. The shape of the smoke changes drastically below the gas pressure of 25 Torr. The width of the smoke at 100 Torr at $10 \mathrm{~mm}$ from the evaporation source is about $7 \mathrm{~mm}$ as seen in Figl(a), but the values become about 1.7 and 3 times greater at gas pressure of 20 Torr and 10 Torr, therefore the density of the decomposed oxygen vapors per unit volume becomes smaller. Sine the melting point of iron is $1536^{\circ} \mathrm{C}$, the decomposed iron gas was condensed as the iron grain near the evaporation source. The decomposed oxygen can be in the state of gas in the flow of Ar gas. Therefore the oxidation of iron took place and oxide grains can be produced in a high gas pressure.

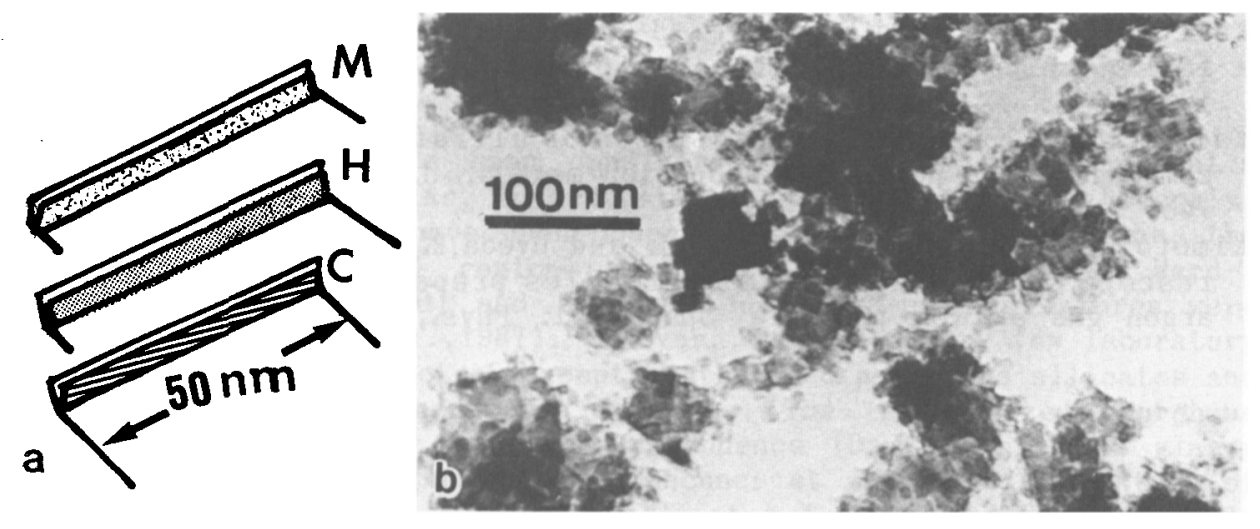

Fig.2. (a) Schematic representation of the production method for MgS.(b) Electron microscopic image.

Fig.2(b) shows MgS grains produced by using the three-heater method which indicated schematically in Fig.2(a). The temperature at locations $5 \mathrm{~mm}$ above and $5 \mathrm{~mm}$ below the heater $\mathrm{H}$ which was heated at $1200^{\circ} \mathrm{C}$ in $\mathrm{Ar}$ gas pressure at 100 Torr became $500^{\circ} \mathrm{C}$ and $300^{\circ} \mathrm{C}$ (Kaito and Saito (1990)). Heaters $M$ and $C$ which were used as the evaporation source of $\mathrm{Mg}$ and $\mathrm{S}$ were set at the above locations. In order to control the vapor pressure of both the $\mathrm{Mg}$ and the $\mathrm{S}$ to bring them closer to the same level, the boat $M$ was heated. When the temperature of the boat $M$ was maintained at about $650^{\circ} \mathrm{C}$, the vapor pressure of $\mathrm{Mg}$ was 2.04 Torr which was nearly same of the vapor pressure of the $S$ at the boat $\mathrm{C}\left(350^{\circ} \mathrm{C}\right)$. The evaporated sulfur vapor rose due to the convective flow from the heater $\mathrm{H}$ and reacted with the $\mathrm{Mg}$ vapor around heater $\mathrm{M}$. 
The shape of the smoke was similar to that shown in Fig.1(a). Since MgS has the crystal structure of $\mathrm{NaCl}$ type, the external shape of the sulfide became a cubic form (Kaito et a1.(1988)). The melting point of $\mathrm{MgS}$ was higher, therefore the surface melting coalescence predominant $1 \mathrm{y}$ took place(Kaito, (1985)). Then the small crystallites were coalesced as seen in Fig.2.

\section{References}

Kaito,C.,(1981) 'Formation of double oxides by coalescence of smoke particles of different oxides', J.Cryst. Growth, 55, 273-280.

Kaito,C.,(1983) 'High resolution electron microscopic study of oxide particles produced by the coalescence of smoke particles of iron and iron oxide', Jpn.J.App1.Phys., 22, L432-L434.

Kaito,C.,(1985) 'Coalescence growth mechanism of smoke particles', Jpn. J. App1. Phys., 24, 261-264.

Kaito,C.,Saito,Y.and Fujita.K.,(1989) 'Studies on the structure and morphology of ultrafine particles of metallic sulfide',J. Cryst. Growth,94, 967-977.

Kaito,C.,Saito,Y. and Fujita,F.,(1988) 'Growth of PbSe and PbTe u1trafine particles by gas evaporation method', Jpn.J.App1. Phys., 27, 1997-1998.

Kaito C.and Saito, Y., (1990) 'Growth of ultrafine particles of II-VI compounds by a new gas evaporation method, J.Cryst. Growth, 99, 743746.

Kimoto,K., Kamiya,Y., Nonoyama,M. and Uyeda,R.,(1963) 'An electron microscope study of fine metal particles prepared by evaporation in argon gas at 1ow pressure' Jpn.J.App1. Phys.,2 ,702-713. 